\title{
Functional and oncological outcomes with male nerve sparing robotic assisted radical cystectomy
}

\author{
Johnraj Kishore Raja Thinagaran ${ }^{1}$, Fouad Maqboul ${ }^{1}$, Zach Dovey ${ }^{1,2}$, Peter Wiklund ${ }^{2}$ \\ 'Department of Urology, Ashford and St. Peter's hospital, Chertsey KT16 OPZ, UK. \\ 2Department of Urology, Mount Sinai Hospital, New York, NY 10029, USA.
}

Correspondence to: Dr. Zach Dovey, Department of Urology, Icahn School of Medicine, Mount Sinai Hospital, 1, Gustav L. Levy Place, New York, NY 10029, USA. E-mail: zachary.dovey@mountsinai.org

How to cite this article: Thinagaran JKR, Maqboul F, Dovey Z, Wiklund P. Functional and oncological outcomes with male nerve sparing robotic assisted radical cystectomy. Mini-invasive Surg 2021;5:46. https://dx.doi.org/10.20517/2574-1225.2021.53

Received: 22 Apr 2021 First Decision: 17 May 2021 Revised: 24 May 2021 Accepted: 26 May 2021 Published: 11 Sep 2021

Academic Editor: Riccardo Autorino Copy Editor: Xi-Jun Chen Production Editor: Xi-Jun Chen

\begin{abstract}
Aim: In keeping with the ethos of surgical oncology, male nerve sparing (NS) robotic assisted radical cystectomy (RARC) aims to maximise functional outcomes without sacrificing oncological outcomes. This review details the surgical technique of male NS RARC as well as discussing strategies that may be employed in tandem with surgery to improve post-operative recovery and longer-term quality of life.
\end{abstract}

Methods: An OVID/EMBASE database search was done with key words of robotic, cystectomy, male and nerve sparing. Publications with no description of post-operative functional outcome were excluded. A total number of 25 relevant publications were selected investigating male NS RARC, assessing functional outcomes along with other surgical standard indicators.

Results: Most series contained small numbers of patients with largely retrospective data and the associated bias of selection. Mean follow up of 27.06 months (range 2.8-58 months) was noted overall. Study design, technique, definitions and measurements of continence and erectile function are heterogeneous across series. With a mean follow up of 27.06 months (range 2.8-58 months), a post-operative satisfactory erectile function of $54.32 \%$ (range 9\%-100\%) and satisfactory day time continence of 90\% (range 54.5\%-100\%) and night time continence of $80.55 \%$ (range $46.7 \%-88 \%$ ) was found with a mean positive surgical margin rate of only $1.8 \%$ (range $0 \%-6.4 \%$ ).

Conclusion: Male NS RARC for appropriately selected patients will offer good functional outcomes. Results from the series reviewed suggest the technique is both feasible and safe, without compromising longer term oncological results.

(C) The Author(s) 2021. Open Access This article is licensed under a Creative Commons Attribution 4.0 International License (https://creativecommons.org/licenses/by/4.0/), which permits unrestricted use, sharing adaptation, distribution and reproduction in any medium or format, for any purpose, even commercially, as long as you give appropriate credit to the original author(s) and the source, provide a link to the Creative Commons license, and indicate if changes were made. 
Keywords: Nerve-sparing, robotic, cystectomy, functional outcomes, continence, erection

\section{INTRODUCTION}

Over 1.72 million people worldwide live with bladder cancer (BC), half of them are from the North America and Europe and men are affected about 4 times more than women ${ }^{[1]}$. BC accounts for the highest lifetime treatment cost per patient among all cancers, with the United States spending $€ 3.6$ billion $^{[2]}$ and Europe another $€ 5$ billion $^{[3]}$ per year on the investigation and management of BC. Though there is a decreasing trend in tobacco use in many parts of the world, overall population growth and increasing longevity has led to a rise in $\mathrm{BC}$ incidence ${ }^{[4]}$, which shows no signs of abating.

Muscle invasive BCs and occasionally high-grade superficial BCs are managed surgically by radical cystectomy. This is a morbid operation with prolonged recovery time and complications that may be long lasting in some patients. Nevertheless, radical cystectomy has evolved greatly over the years with improvement in knowledge, skills and technology. Marshall and Whitmore ${ }^{[5]}$ provided the first detailed description of a radical cystoprostatectomy and pelvic lymph node dissection in 1949. After Clayman performed the first laparoscopic nephrectomy in 1991, a minimally invasive approach was promoted by urologists for various procedures. More complicated operations like prostatectomy were also performed laparoscopically, but minimally invasive surgery really came into its own when the da Vinci Surgical System (Intuitive Surgical, Sunnyvale, CA) came into play ${ }^{[6]}$. With the advent of robotic assistance in urology and the emergence of robotic assisted radical cystectomy (RARC), allowing better dexterity and visibility, the boundaries have been pushed and expectations have improved.

Although there are similarities in some of the basic technical aspects of nerve sparing (NS) for a radical prostatectomy and a radical cystectomy, there are also some key differences; notwithstanding the potential for urothelial cancer to be more lethal than prostate cancer. This makes patient selection for NS in RARC particularly important. However, there is a reasonable body of evidence establishing the short term $(\leq 5$ years) oncologic safety of performing a NS operation for bladder cancers ${ }^{[7,8]}$, which has encouraged UroOncologists to increase the application of this approach in their practice. This review aims to study the technique of male NS RARC, review the results now available in the literature, and examine the status of their functional outcomes and survival outcomes with longer term follow up. Before this, the neuroanatomy of the pelvic plexus will be discussed to provide an understanding of how the technical approach to NS during RARC has developed.

\section{METHODS}

\section{Neuroanatomy of the pelvic plexus}

The neuroanatomy of the pelvic plexus was originally described in a landmark paper by Walsh and Donker $^{[9]}$ in 1982, studying nerves that supply the penis and pelvic organs in males stillborn at birth. Sympathetic input to pelvic plexus arises from T11-L2 and stimulates ejaculation as well as increasing the bladder neck and urethral tone by inducing contraction of the smooth musculature. Parasympathetic input arises from S2-4 with fibres joining the pelvic plexus and controlling bladder muscle contraction and erectile function. Nerve fibres originating from the pelvic plexus are generally unmyelinated ${ }^{[10]}$. Tewari further described the surgical neuro-anatomy of the pelvic plexus, dividing it into three distinct zones, that all may be injured during dissection, and thus cause postoperative erectile dysfunction ${ }^{[11]}$. In broad terms the plexus lies in the subperitoneal tissue near the pelvic ureter and its relation to the vas deferens, and extends forward in a rectangular shape over the lateral and posterior parts of the seminal vesicles (SVs). Its three surgically distinct zones include the proximal neurovascular plate (PNP), containing the cell bodies of the 
pelvic plexus, which is in close proximity to the SVs as above, the predominant neurovascular bundle (PNVB) in the groove between posterolateral prostate and rectum, and the accessory nerve pathways (ANPs) on the lateral surface of the prostate in the lateral prostatic fascia ${ }^{[10,11]}$. During surgical dissection, injury caused by direct trauma or cautery, inflammation, or ischaemia to any of the nerve fibres is potentially reversible, but cell body injuries are not. The pudendal nerve, with somatic cell fibres from Onuf s nucleus in the anterior horn of S2-4, supplies the pelvic floor muscles and external sphincter. In the context of male NS RARC, this is relevant to neobladder operations, where injury to its nerve branches when dissecting and ligating the dorsal vein complex, may compromise post-operative continence ${ }^{[10]}$. A detailed knowledge of the neuroanatomy will provide the operating surgeon with direction when dissecting around the SVs, base of prostate and distally towards the prostatic apex, in order to achieve the most effective NS whilst proceeding through the steps of RARC described below.

\section{Patient preparation and selection}

Patient selection is crucial to surgical planning, especially for the NS approach, with some basic contraindications when considering the RARC part as well as more specific criteria for NS. Moreover, the decision to proceed with NS may be made in conjunction with consideration for orthotopic neobladder, which will also require specific criteria for patient selection. Generally, depending on the surgeon's experience, relative contraindications to RARC would include BMI $>35$, severe vasculopathy with a history of surgery, severe cardiorespiratory illness, prior pelvic trauma, surgery or radiation, and locally advanced diseas $^{[12]}$. For male NS, preoperative potency is a basic requirement, with a desire for ongoing sexual activity postoperatively. Some studies have suggested an age cut off of 65 years, based on poorer recovery in older age groups ${ }^{[13]}$, but if patients have reasonable preoperative potency, and otherwise are suitable for selection, age should not be a factor in the decision-making process. Positive surgical margin rates have been noted to rise with increasing tumour stage ${ }^{[14]}$, and clinical tumour stage should be T2 or less. Some groups also suggest clinical evidence of prostate cancer should be a contraindication ${ }^{[15]}$, but if this has been proven as localized or low volume intermediate risk prostate cancer by preoperative prostate biopsy and multiparametric Magnetic Resonance Imaging prostate, NS may still be undertaken. If orthotopic neobladder is also being considered, patients require unimpaired renal and liver function, no history of urethral sphincter injury, the necessary motivation and cognitive function to undertake the postoperative neobladder training protocols as well as the dexterity to perform intermittent self-catheterization ${ }^{[16]}$.

Preoperative preparation for patients in modern robotic centres will include application of enhanced recovery after surgery (ERAS) protocols, as well as advice regarding preoperative lifestyle changes and physical activity in what is now termed "prehabilitation", which aims to maximise postoperative recovery. This is discussed in more detail in the section below. For ERAS protocols, which most robotic centres will have in place, patients are educated and counselled regarding the procedure and recovery, medically optimized, and encouraged to change their diet preoperatively to include carbohydrate loading. Preoperative low residue diet for $24 \mathrm{~h}$ with $6 \mathrm{~h}$ fasting for solids and $2 \mathrm{~h}$ for fluids is also recommended.

\section{Surgical technique for male RARC}

Applying a modular approach to the technique of male RARC has a number of advantages. It provides a methodical step by step perspective to the procedure that facilitates learning, allows smooth progress through what is a lengthy procedure, allows the operating surgeon be aware of specific steps that may have complications which can be avoided, and ultimately may reduce operating time as experience is gained ${ }^{[12]}$. Male RARC include the steps of ureteric dissection, dissection of the anterior rectal space, dissection of the lateral rectal space, mobilization of the bladder and urethral transection, extended lymph node dissection (ELND), specimen removal, and urinary diversion. These sections will be discussed individually, before discussing specific techniques for NS (see Figures 1-16). 


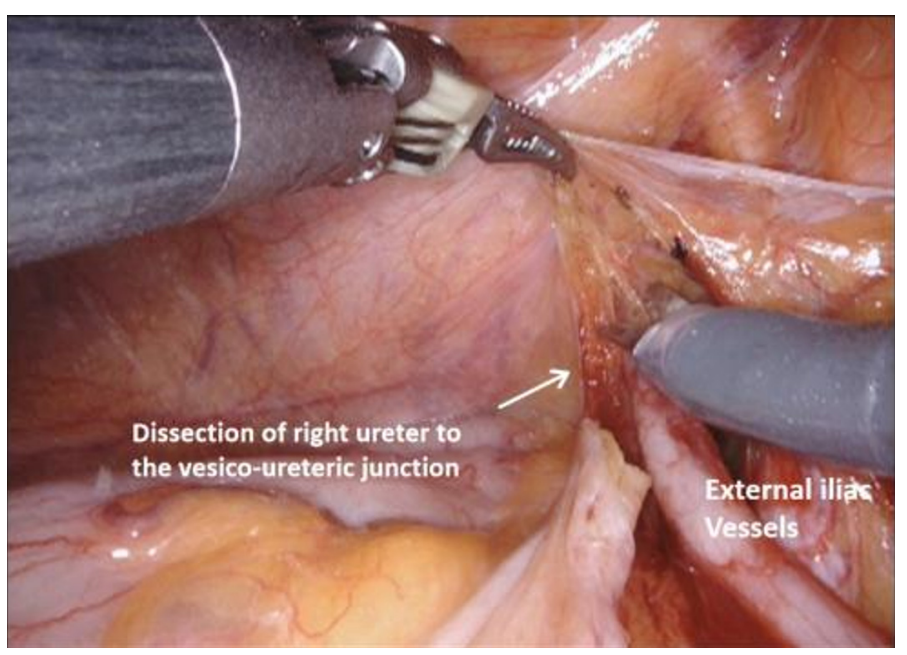

Figure 1. Right ureteric dissection.

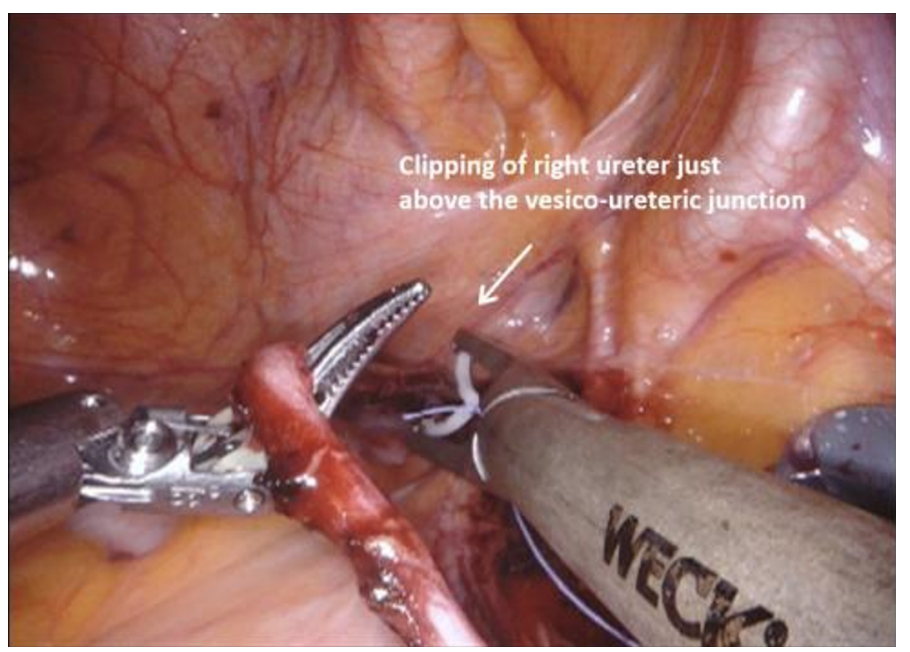

Figure 2. Clipping of the right ureter just above the right vesico-ureteric junction.

Following informed consent, once in the operating room the patient receives a general anaesthetic and is then placed in lithotomy position with maximal Trendelenburg tilt. With arms fixed to the side of the body, a pneumatic calf compressor is attached and the upper torso covered by a warming blanket. Broad spectrum antibiotic prophylaxis is administered at induction. Per-urethral bladder catheter is placed. Thromboprophylaxis is given in recovery, and continued for 1 month postoperatively.

\section{Trocar placement}

This is similar to a robotic prostatectomy, but the trocar placement is shifted cranially. An $8 \mathrm{~mm}$ camera port is inserted at a left paramedian point $5-6 \mathrm{~cm}$ above the umbilicus, with 2 further $8 \mathrm{~mm}$ robotic ports placed $8-10 \mathrm{~cm}$ on either side, at the level of umbilicus. A further $8-10 \mathrm{~cm}$ lateral to the left port, a $15 \mathrm{~mm}$ port is inserted, $2-3 \mathrm{~cm}$ superomedial to the left anterior superior iliac spine (ASIS). This is later used to pass the bowel staplers and also serves as the port for the 4 th arm. There are 2 other $12 \mathrm{~mm}$ assistant ports, one between the camera and the right robotic port and another one $2-3 \mathrm{~cm}$ superomedial to the right $\mathrm{ASIS}^{[12]}$. 


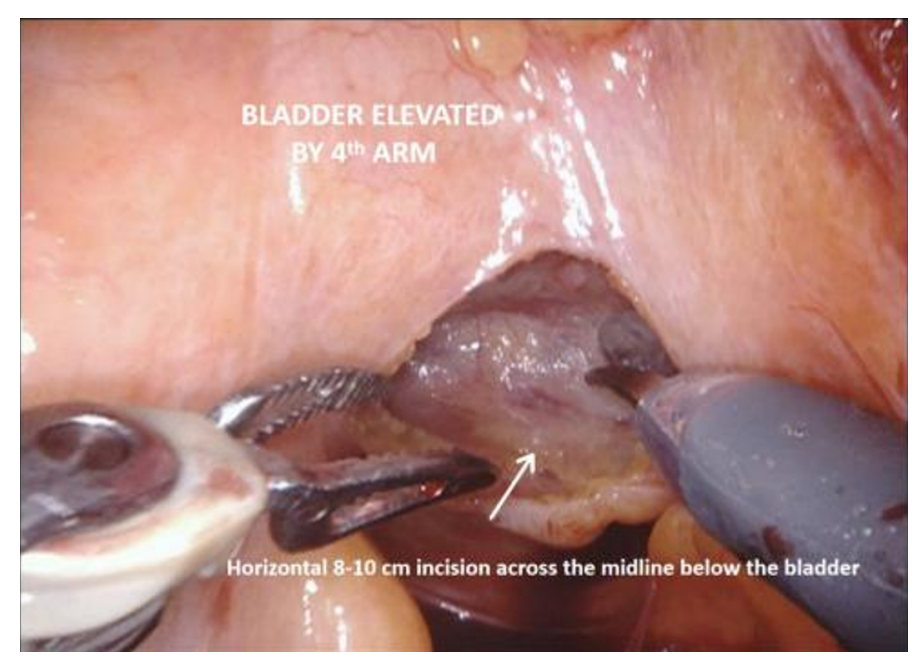

Figure 3. Posterior dissection, with horizontal incision of peritoneum just below the elevated bladder.

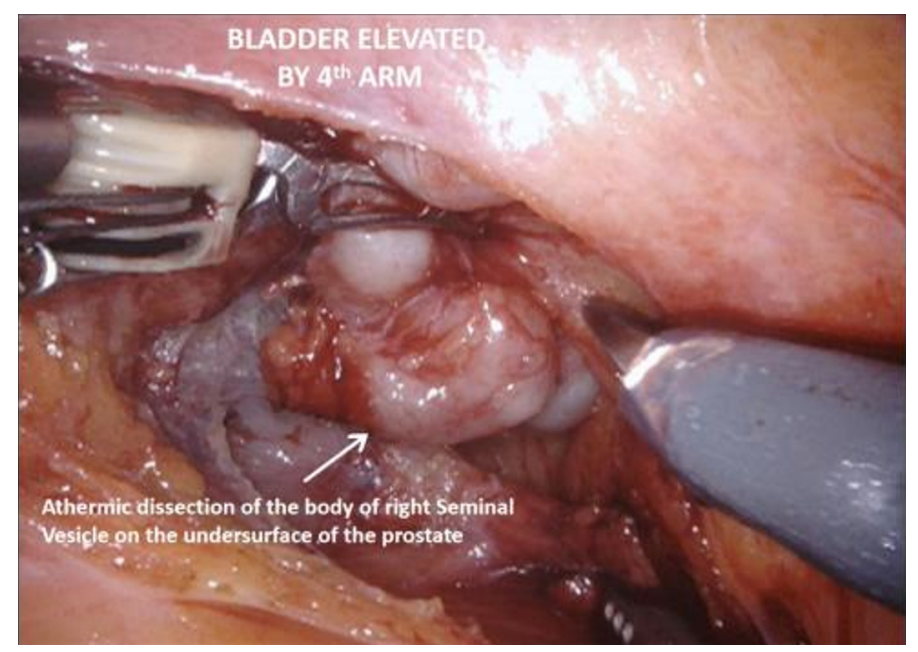

Figure 4. Posterior dissection, with athermic dissection of the body of the right seminal vesicle.

\section{Ureteric dissection}

The operation begins with dissection and division of the distal end of the ureters with clips bilaterally, generally first on the right side as the sigmoid colon may be attached to the peritoneum on this side and require adhesiolysis. The ureters can be found entering the pelvis beneath the peritoneum overlying the bifurcation of the common iliac vessels. Incising the peritoneum at this point may reveal their location, and the fourth arm is helpful in retracting the sigmoid colon on the left side. When dissecting distally towards the uretero-vesical junction, it is important to minimize handling of the ureters and leave as much tissue on them as possible to prevent compromising the blood supply and reducing the risk of ureteric strictures long term.

\section{Anterior rectal space}

The vasa are localized crossing from lateral to medial beneath the peritoneum, towards the SVs. The fourth arm is used to elevate the peritoneum and then an $8-10 \mathrm{~cm}$ incision is made horizontally across the midline below the bladder, extending proximally on either side towards the bifurcation of the common iliac vessels. 


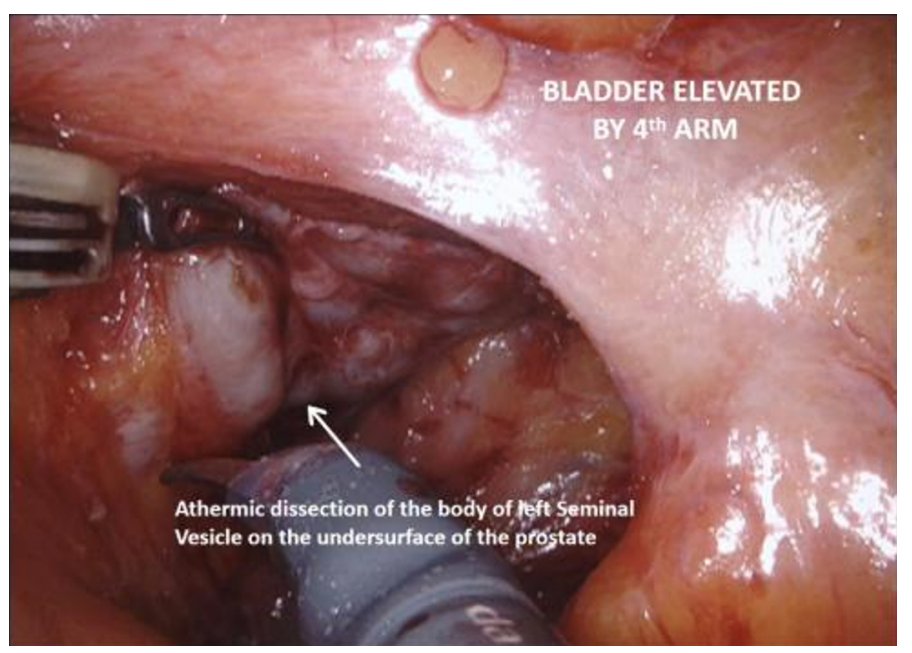

Figure 5. Posterior dissection, with athermic dissection of the body of the left seminal vesicle.

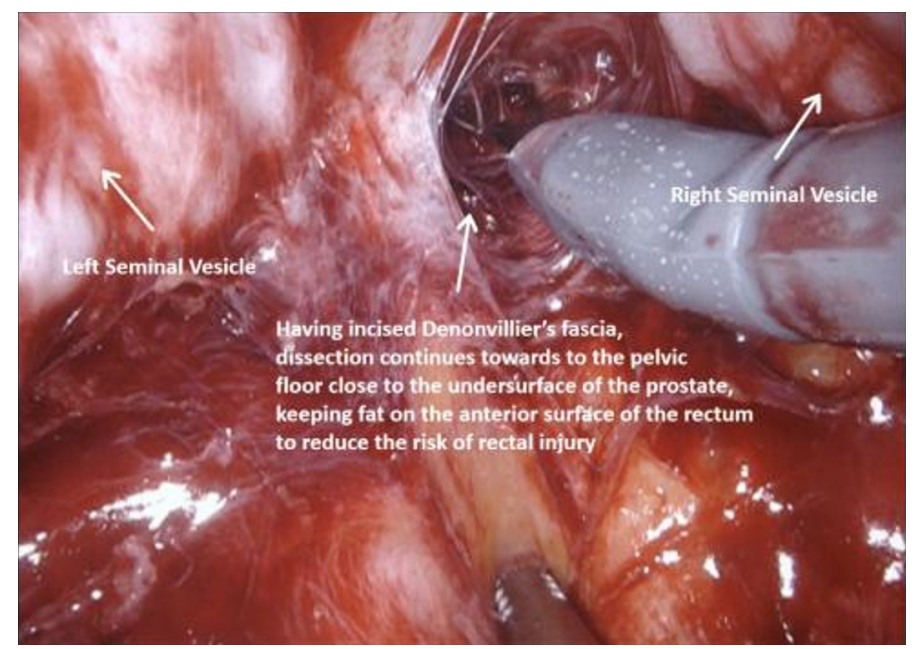

Figure 6. Post dissection, with incision of Denonvillier's fascia, and further dissection towards the pelvic floor close to the undersurface of the prostate. Fat is left on the anterior surface of the rectum to reduce the risk of rectal injury.

The vasa are then divided and the SVs dissected, avoiding cautery and using clips to divide vessels, to avoid injury to the cell bodies of the pelvic plexus. Once Denonvillier's fascia is exposed, this is divided and the plane posterior to the prostate is opened, continuing down to the pelvic floor. Preserving the fat anterior to the rectum helps to prevent rectal injury.

\section{Lateral rectal space}

Next the peritoneum lateral to the umbilical ligaments is incised, and retzius space is opened down to the pelvic floor, revealing the endopelvic fascia. The bladder is still attached by the urachus to the anterior abdominal wall and is elevated and put under traction by the fourth arm. Coming back to the lateral pedicle, the superior vesical artery is isolated, and can be divided between Hem-o-lok ${ }^{\oplus}$ clips or by LigaSure ${ }^{\text {tw }}$ instrument. The anterior division of the internal iliac artery can be seen, which gives rise to the inferior vesical artery. This then divides into the urethral artery and capsular arteries, the latter of which are preserved because they contribute to the PNVB. The inferior vesical and urethral artery may be clipped or divided by LigaSure ${ }^{\mathrm{m}}$ as above. Moving down to the pelvic floor, the lateral aspects of the prostate are 


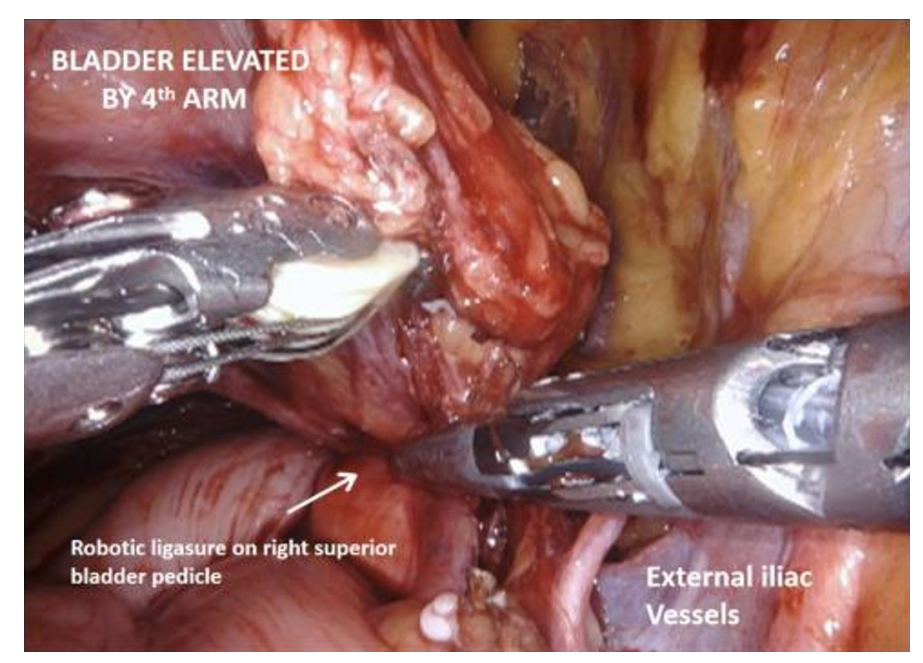

Figure 7. Ligasure of right superior bladder pedicle.

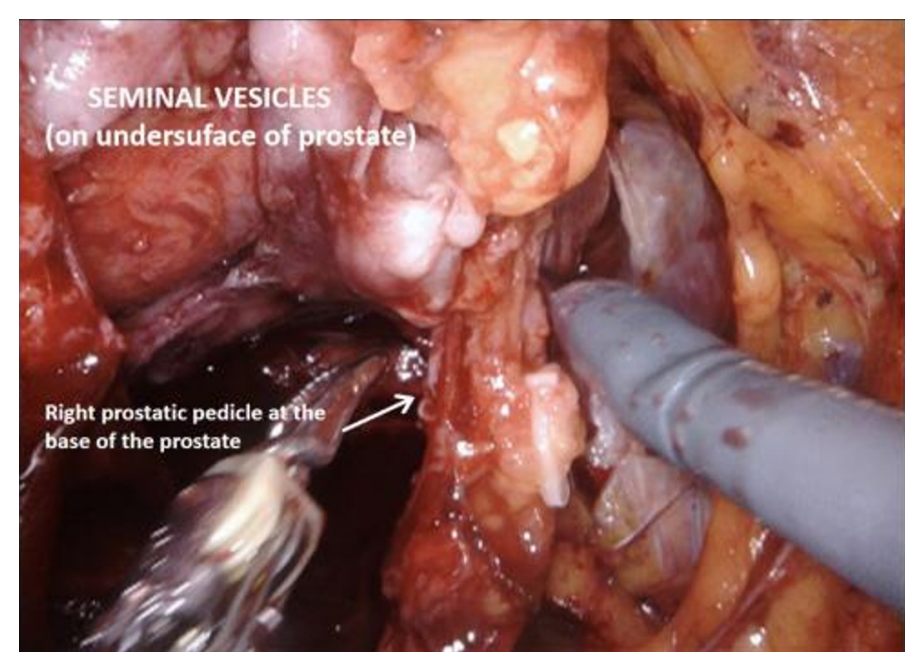

Figure 8. Ligasure of right prostatic pedicle at the base of the prostate.

mobilized and the endopelvic fascia may be opened, which frees the apex of the prostate with puboprostatic ligaments, urethra and dorsal vein complex. This is an area familiar to prostatectomists, and careful dissection in this area is crucial to functional outcomes.

\section{Urethral transection and mobilisation of the bladder}

The medial umbilical ligament and urachus are divided to free the bladder from the anterior abdominal wall, which allows easier dissection of the prostatic apex. During this part of the procedure, it is important to avoid injury to the inferior epigastric vessels. The pneumoperitoneum is increased to $20 \mathrm{mmHg}$, and the dorsal vein complex is ligated and divided, revealing the underlying urethra. If an intracorporeal neobladder is planned, urethral transection aims to preserve as much urethral length as possible, and a urethral margin specimen is sent for frozen section to rule out urethral tumour invasion. The urethra with catheter in situ is clipped and divided which prevent tumour spillage from the radical cystectomy specimen. 


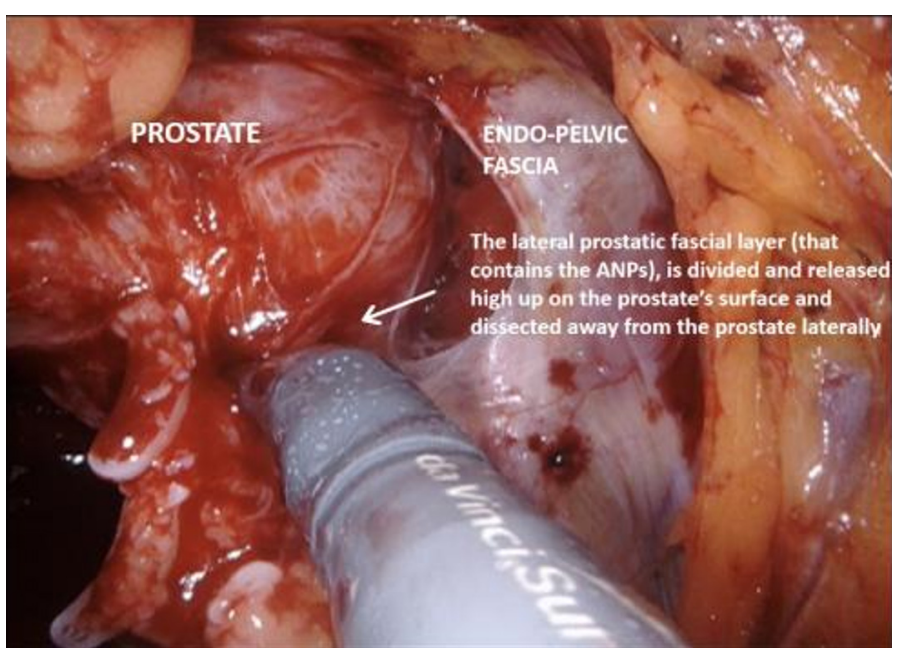

Figure 9. High release of the lateral prostatic fascia containing putative accessory nerve pathways (ANPs), with subsequent dissection of the neurovascular bundle laterally, away from the prostate.

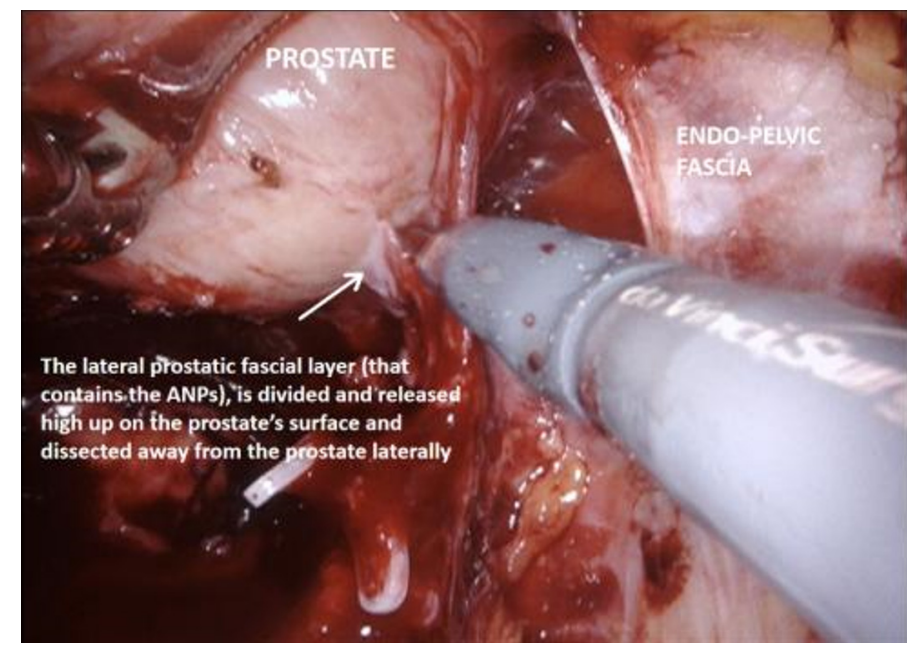

Figure 10. Further dissection of the lateral prostatic fascia and neurovascular bundle laterally, away from the prostate.

\section{Extended lymph node dissection}

This is generally performed once the cystectomy is complete so that right and left en bloc lymph node packets can be removed together with the radical cystectomy specimen. The specific technique for ELND is not discussed in this article; suffice to say sparing LNs near the vesico-ureteric junction at superior pedicle will limit injury to the hypogastric nerves carrying sympathetic fibres to the pelvic plexus ${ }^{[17]}$.

\section{Specimen removal}

The radical cystectomy specimen is placed in a large endo catch bag, with similar but smaller bags for each lymph node packet. The three bags are clipped together and can be removed through the camera port incision prior to proceeding to the urinary diversion if they are to be sent for biobanking, or alternatively can be removed through the same incision at the end of the procedure. 


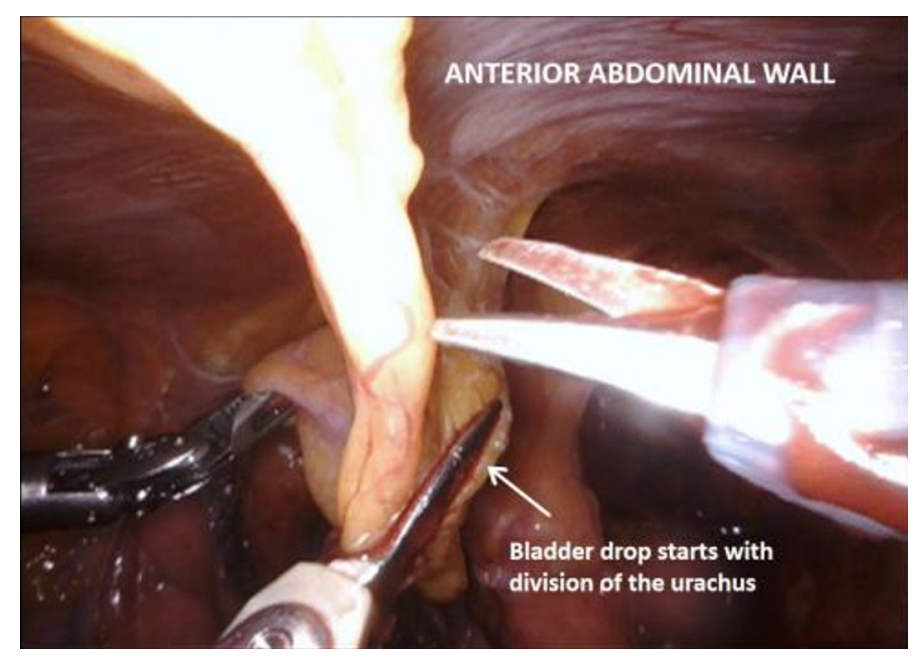

Figure 11. Bladder drop with division of the urachus.

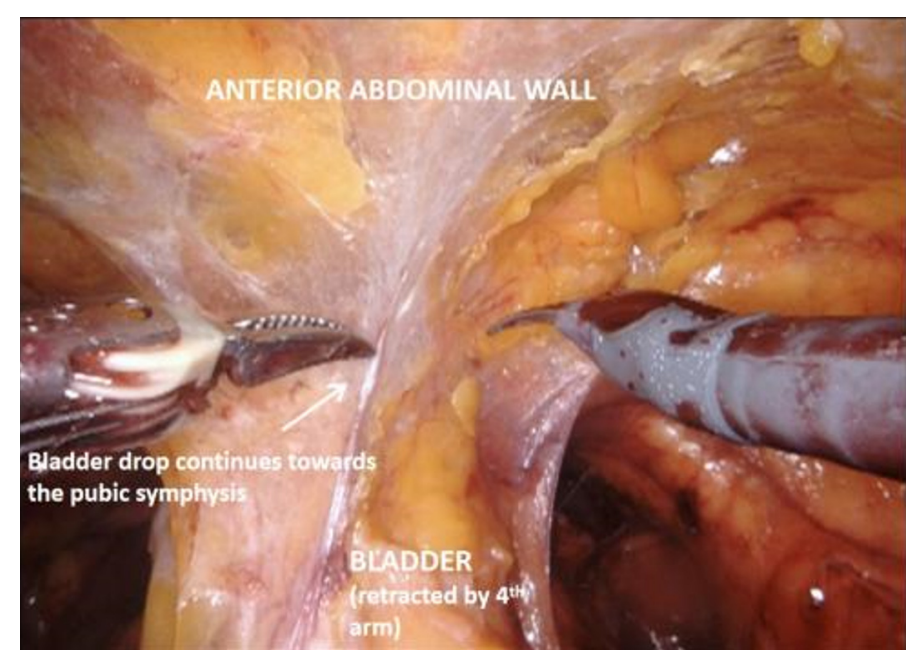

Figure 12. Bladder drop with dissection continuing down to the pubic symphysis.

\section{Urinary diversion}

The next step is the urinary diversion, which is commonly either ileal conduit or orthotopic neobladder. The neobladder is in keeping with a NS approach by aiming to maximise functional outcomes with minimal effect on body image, analogous to the pelvic organ sparing approach in women. By avoiding a urostomy bag, as well as reducing the risk of erectile dysfunction as much as possible, the combined result of male NS and neobladder will facilitate a return to sexual activity.

\section{Nerve sparing technique}

With the trizonal neuroanatomy described above in $\operatorname{mind}^{[11]}$, the NS technique begins once the SVs dissection starts. Avoidance of cautery and clipping small vessels for hemostasis prevents injury to the cell bodies in the PNP, especially around the middle and the tips of the SVs. As the dissection continues forward, vessels may be clipped as close as possible to the prostate, again avoiding cautery with athermal dissection. Once at the base of the prostate, the lateral fascial layer that contains the ANPs, is divided and released high up on the prostate's surface and dissected away from the prostate laterally, to prevent injury to 


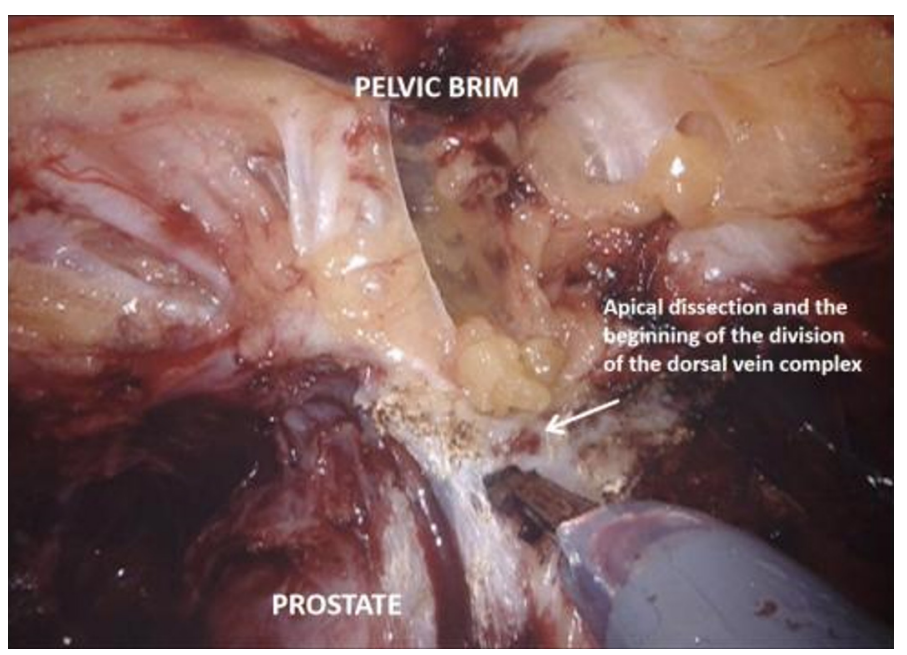

Figure 13. Dissection of the prostatic apex before division of the dorsal vein complex.

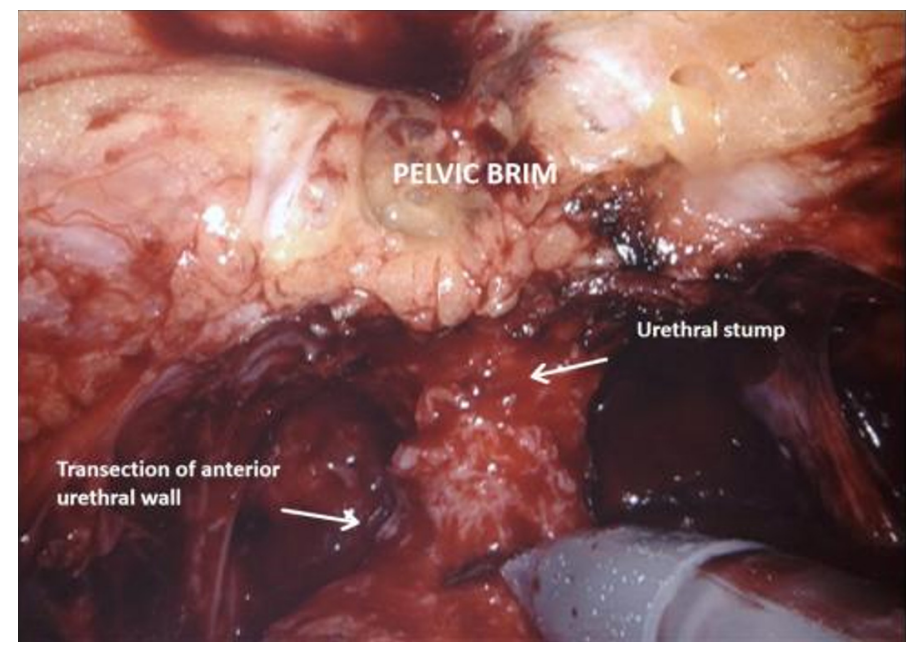

Figure 14. Transection of the anterior urethral wall.

the ANPs. Further inferiorly the PNVB may be seen and is also dissected away from the prostate laterally, with as little tension and cautery as possible. Once this plane is found, dissection continues towards the prostatic apex, with the lateral prostatic fascia and PNVB laterally, down to the pelvic floor, until the prostate-urethral junction. At the apex, the PNVBs run alongside the urethra at 10 and 2 o'clock, and careful suturing of the dorsal vein should avoid these areas, as well as making sure to minimize dissection around the surrounding structures and muscle tissue to prevent injuring branches of the pudendal nerves and accessory vessels ${ }^{[17]}$. A continuing awareness for nerve preservation is important during the ELND, where sparing lymph nodes at the lateral pedicle between the ureters and bladder near the vesico-ureteric junction prevents injury to the hypogastric nerves carrying sympathetic fibres to the pelvic plexus (described above) $)^{[17]}$.

\section{Technical variations on NS}

Two variations on the common NS approach have also been described including capsule sparing cystectomy and SV sparing cysto-prostatectomy ${ }^{[15]}$. The capsule sparing technique involves a pre cystectomy 


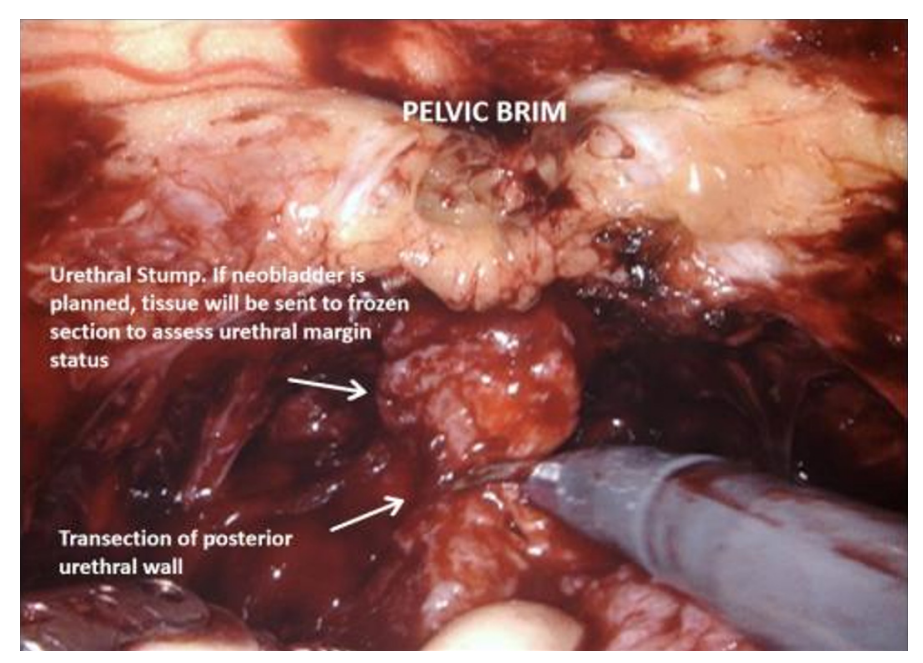

Figure 15. Transection of the posterior urethral wall.

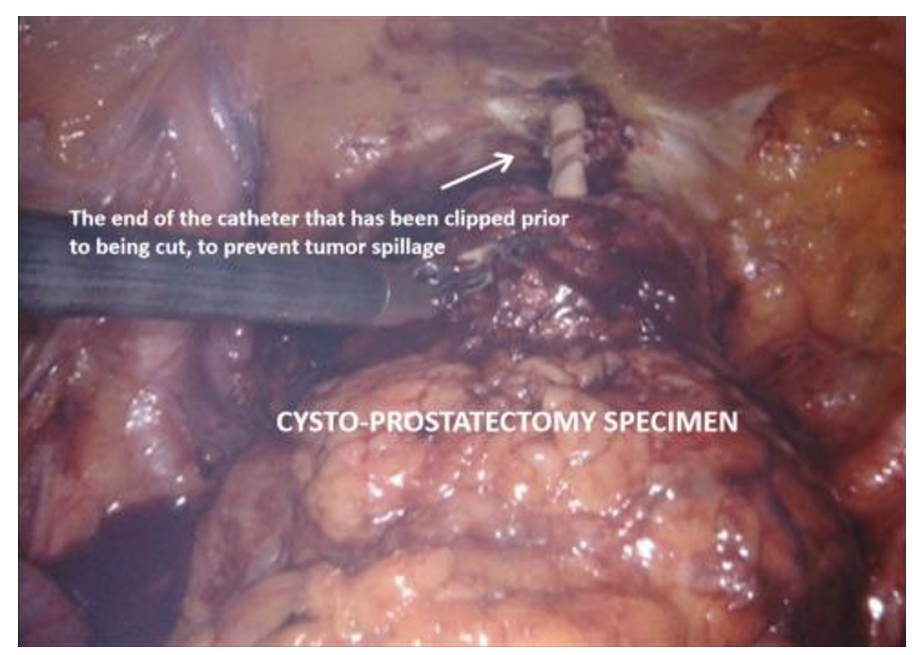

Figure 16. Cysto-prostatectomy specimen.

transurethral resection of prostate and prostate biopsies to rule out prostate cancer, followed by RARC with preservation of prostate capsule, vasa and SVs with the trizonal pelvic plexus remaining intact ${ }^{[15,18]}$. In a prospective randomised controlled trial, no significant difference in functional outcomes was seen between this approach and the commoner NS approach above ${ }^{[19]}$. For the SV sparing technique, the prostatectomy part of the cysto-prostatectomy is down by retrograde intrafascial dissection sparing the vasa, SVs and once again, the trizonal architecture of the pelvic plexus. This technique was undertaken by some of the series presented in Table 1 , with satisfactory outcomes ${ }^{[18,20]}$, but more study is required to determine whether this technique is superior to the more standard approach.

\section{RESULTS (SEE Appendix 1, Tables 1 AND 2)}

An EMBASE database search was done with key words of robotic, cystectomy, male and nerve sparing, which included journal articles, abstract publications or conference abstracts, available in English or translated to English. Previous review articles were also checked as sources of original work not otherwise found on initial search. Duplications and publications with no description of post-operative functional 
Table 1. Functional outcomes

\begin{tabular}{|c|c|c|c|c|c|c|c|}
\hline Ref. & Year & Type of study & $\begin{array}{l}\text { No. of male } \\
\text { patients }\end{array}$ & $\begin{array}{l}\text { Nerve } \\
\text { sparing }\end{array}$ & Continence & Sexual function & $\begin{array}{l}\text { Duration of } \\
\text { follow-up } \\
\text { (months) }\end{array}$ \\
\hline Balbay et al. ${ }^{[21]}$ & 2020 & Case series & 18 & $77.78 \%$ & $\begin{array}{l}\text { DT }-76.92 \% \\
\text { NT - } 53.85 \%\end{array}$ & $\begin{array}{l}\text { Baseline decrease } \\
\text { by } 15 \text { points }\end{array}$ & 47.3 \\
\hline Gok et al. ${ }^{[22]}$ & 2019 & $\begin{array}{l}\text { Retrospective } \\
\text { analysis }\end{array}$ & 92 & $90.8 \%$ & $\begin{array}{l}\text { DT }-65 \% \\
\text { NT }-42 \%\end{array}$ & $\begin{array}{l}\text { Baseline decrease } \\
\text { by } 24 \text { points }\end{array}$ & 27.1 \\
\hline Liu et al. ${ }^{[23]}$ & 2019 & Case series & 12 & $100 \%$ & ND & $\begin{array}{l}S=41.7 \% \\
I=25 \% \\
N=33.3 \%\end{array}$ & 12 \\
\hline Zarranz et al. ${ }^{[24]}$ & 2019 & Case series - CA & 46 & $67.39 \%$ & ND & $\mathrm{S}=91 \%$ of $\mathrm{NS}$ & 24 \\
\hline Kwon et al. ${ }^{[25]}$ & 2018 & $\begin{array}{l}\text { Retrospective } \\
\text { cohort - CA }\end{array}$ & 40 & $37.5 \%$ & ND & $40 \%$ & 12 \\
\hline Palou et al. ${ }^{[39]}$ & 2017 & Case report - CA & 1 & $100 \%$ & $100 \%$ & IIEF 17 & 7 \\
\hline Asimakopoulos et al. ${ }^{[17]}$ & 2016 & Case series & 40 & $100 \%$ & $\begin{array}{l}\text { DT }-75 \% \\
\text { NT }-72.5 \%\end{array}$ & $77.5 \%$ & 26.5 \\
\hline Nyame et al. ${ }^{[26]}$ & 2016 & Case series & 3 & $100 \%$ & $100 \%$ & $100 \%$ & 28.2 \\
\hline Colombo et al. ${ }^{[18]}$ & 2015 & $\begin{array}{l}\text { Retrospective } \\
\text { analysis }\end{array}$ & 90 & $100 \%$ & $\begin{array}{l}\text { DT }-88.8 \% \\
\text { NT }-84.4 \%\end{array}$ & $65 \%$ & 58 \\
\hline Jacobs et al. ${ }^{[19]}$ & 2015 & $\begin{array}{l}\text { Randomised } \\
\text { controlled trial }\end{array}$ & 40 & $100 \%$ & $\begin{array}{l}\text { Baseline decrease by } \\
20 \pm 31 \text { points }\end{array}$ & $\begin{array}{l}\text { Baseline decrease } \\
\text { by } 12 \pm 20 \text { points }\end{array}$ & 38 \\
\hline Schwentner et al. ${ }^{[29]}$ & 2015 & $\begin{array}{l}\text { Retrospective } \\
\text { analysis }\end{array}$ & 50 & $92 \%$ & $\begin{array}{l}\text { DT - } 88 \% \\
\text { NT - } 55.1 \% \text { overall }\end{array}$ & $54 \%$ overall & 30.3 \\
\hline Haberman et al. ${ }^{[27]}$ & 2014 & $\begin{array}{l}\text { Retrospective } \\
\text { analysis }\end{array}$ & 254 & $11.42 \%$ & ND & $\begin{array}{l}S-45 \% \\
I-21 \% \\
N-34 \%\end{array}$ & 32.9 \\
\hline Menon et al. ${ }^{[28]}$ & 2003 & Case series - CA & 2 & $100 \%$ & ND & $\begin{array}{l}I=100 \% \\
\text { IIEF score of } 9 \& 10\end{array}$ & 2.8 \\
\hline Krishnan et al. ${ }^{[30]}$ & 2014 & Case series & 3 & $100 \%$ & $100 \%$ & $100 \%$ & ND \\
\hline Tyritzis et al. $^{[38]}$ & 2013 & $\begin{array}{l}\text { Retrospective } \\
\text { analysis }\end{array}$ & 62 & $66.13 \%$ & $\begin{array}{l}\text { DT }-88.2 \% \\
\text { NT }-73.5 \%\end{array}$ & $84.37 \%$ & 12 \\
\hline Rey et al. ${ }^{[31]}$ & 2013 & Case report - CA & 1 & $100 \%$ & $100 \%$ & $100 \%$ & 24 \\
\hline Boc et al. ${ }^{[32]}$ & 2013 & Case series - CA & 2 & $100 \%$ & ND & $100 \%$ & 6 \\
\hline Canda et al. ${ }^{[40]}$ & 2012 & Case series & 25 & $92 \%$ & $\begin{array}{l}\text { DT }-73.3 \% \\
\text { NT }-46.7 \%\end{array}$ & ND & 6.3 \\
\hline Jonsson et al. ${ }^{[33]}$ & 2011 & $\begin{array}{l}\text { Prospective } \\
\text { nonrandomised }\end{array}$ & 36 & $55 \%$ & $\begin{array}{l}\text { DT }-83 \% \\
\text { NT }-66 \%\end{array}$ & $75 \%$ & 25 \\
\hline Akbulut et al. ${ }^{[34]}$ & 2011 & Case series & 12 & $91.67 \%$ & $\begin{array}{l}\text { DT - } 54.5 \% \\
\text { NT - ND }\end{array}$ & $9 \%$ & 7.1 \\
\hline Ong et al. ${ }^{[20]}$ & 2010 & Case series & 31 & $100 \%$ & $\begin{array}{l}\text { DT }-93 \% \\
\text { NT }-66 \%\end{array}$ & $79 \%$ & 18 \\
\hline Palou et al. ${ }^{[35]}$ & 2010 & Case series & 12 & $100 \%$ & $\begin{array}{l}\text { DT }-90.9 \% \\
\text { NT }-72.72 \%\end{array}$ & $90.9 \%$ & 16.5 \\
\hline Murphy et al. ${ }^{[36]}$ & 2008 & Case series & 23 & $20 \%$ & $\begin{array}{l}\text { DT - } 100 \% \\
\text { NT }-75 \%\end{array}$ & $75 \%$ & 17 \\
\hline Mottrie et al. ${ }^{[37]}$ & 2007 & Case series & 27 & $25.9 \%$ & $86 \%$ & $86 \%$ & 10.2 \\
\hline Kessler et al. ${ }^{[13]}$ & 2004 & $\begin{array}{l}\text { Retrospective } \\
\text { analysis }\end{array}$ & 331 & $77.34 \%$ & $\begin{array}{l}\text { DT }-96 \% \\
\text { NT }-88 \%\end{array}$ & $35.93 \%$ & 24 \\
\hline
\end{tabular}

CA: Conference abstract; ND: not described; DT: day time; NT: night time; S: satisfactory: I: insufficient; N: no erection; NS: nerve sparing.

outcome were excluded. When there was no mention about any sparing of the neurovascular bundles (NVBs), the procedure was taken a non-nerve-sparing procedure and thus also excluded along with the procedures performed without robotic assistance. A total number of 25 relevant publications were selected investigating male NS RARC, assessing functional outcomes with respect to potency and urinary continence along with other surgical standard indicators. 
Table 2. Perioperative and oncological outcomes

\begin{tabular}{|c|c|c|c|c|c|c|}
\hline Ref. & Year & $\begin{array}{l}\text { No. of male } \\
\text { patients }\end{array}$ & Complications & $\begin{array}{l}\text { Positive } \\
\text { surgical } \\
\text { margins }\end{array}$ & Survival rates & $\begin{array}{l}\text { Duration of follow- } \\
\text { up (months) }\end{array}$ \\
\hline Balbay et al. ${ }^{[21]}$ & 2020 & 18 & $\begin{array}{l}\text { Early - } 9 \%(\geq \mathrm{Gr} 3) \\
\text { Late - } 18 \%(\geq \mathrm{Gr} 3)\end{array}$ & $13.6 \%$ & $\begin{array}{l}\text { CSS, OS \& RFS at } 2 \text { years - } \\
68.6 \%, 66.0 \% \& 69.7 \%\end{array}$ & 47.3 \\
\hline Gok et al. ${ }^{[22]}$ & 2019 & 92 & $\begin{array}{l}\text { Early }-20.4 \% \\
(\geq \mathrm{Gr} 3) \\
\text { Late }-7.1 \%(\geq \mathrm{Gr} 3)\end{array}$ & $2 \%$ & $\begin{array}{l}\text { OS \& CSS at } 25 \text { months - } \\
20.4 \% \& 13.3 \%\end{array}$ & 27.1 \\
\hline Liu et al. ${ }^{[23]}$ & 2019 & 12 & None & Nil & ND & 12 \\
\hline Zarranz et al. ${ }^{[24]}$ & 2019 & 46 & Transfusion 35\% & Nil & PFS at 2 years $71 \%$ & 24 \\
\hline Kwon et al. ${ }^{[25]}$ & 2018 & 40 & ND & ND & OS \& CSS at 5 years $86.7 \%$ & 12 \\
\hline Palou et al. ${ }^{[39]}$ & 2017 & 1 & Ileus - 2 days & ND & $100 \%$ & 7 \\
\hline Asimakopoulos et al. ${ }^{[17]}$ & 2016 & 40 & $\begin{array}{l}\text { Early }-30 \%, 2.5 \% \\
(\geq \mathrm{Gr} 3) \\
\text { Late }-32.5 \%, 5 \% \\
(\geq \mathrm{Gr} 3)\end{array}$ & $2.5 \%$ & 1 death at 23 months & 26.5 \\
\hline Nyame et al. ${ }^{[26]}$ & 2016 & 3 & $2(66 \%) \mathrm{Gr} 2$ & Nil & $100 \%$ & 28.2 \\
\hline Colombo et al. ${ }^{[18]}$ & 2015 & 90 & ND & ND & CSS $-92.2 \%$ & 58 \\
\hline Jacobs et al. ${ }^{[19]}$ & 2015 & 40 & $47.5 \%(\geq \mathrm{Gr} 3)$ & $5 \%$ & ND & 38 \\
\hline Schwentner et al. ${ }^{[29]}$ & 2015 & 50 & $25.8 \%(\geq \mathrm{Gr} 3)$ & $6.4 \%$ & $\begin{array}{l}\text { CSS }-84 \% \\
\text { OS }-71 \%\end{array}$ & 30.3 \\
\hline Menon et al. ${ }^{[28]}$ & 2003 & 2 & $100 \%$ Gr1 & ND & ND & 2.8 \\
\hline Krishnan et al. $^{[30]}$ & 2014 & 3 & ND & $\mathrm{Nil}$ & $100 \%$ & ND \\
\hline Tyritzis et al. ${ }^{[38]}$ & 2013 & 62 & $\begin{array}{l}\text { At } 90 \text { days } 58.5 \% \\
\text { overall } \\
37.1 \%(\geq \mathrm{Gr} 3)\end{array}$ & $1.4 \%$ & OS \& CSS at 2 years $-88.9 \%$ & 12 \\
\hline Rey et al. ${ }^{[31]}$ & 2013 & 1 & None & Nil & $100 \%$ & 24 \\
\hline Boc et al. ${ }^{[32]}$ & 2013 & 2 & ND & Nil & $100 \%$ & 6 \\
\hline Canda et al. ${ }^{[40]}$ & 2012 & 25 & $\begin{array}{l}\text { Early }-16 \%(\geq \mathrm{Gr} 3) \\
\text { Late }-12 \%(\geq \mathrm{Gr} 3)\end{array}$ & $\mathrm{Nil}$ & CSS $-82.6 \%$, OS $-78.26 \%$ & 6.3 \\
\hline Jonsson et al. ${ }^{[33]}$ & 2011 & 36 & $\begin{array}{l}\text { Early }-40 \% \\
\text { Late - } 33 \%\end{array}$ & $2.78 \%$ & 3 years CSS $-86 \%$ & 25 \\
\hline Akbulut et al. ${ }^{[34]}$ & 2011 & 12 & $16.6 \%(\geq \mathrm{Gr} 3)$ & Nil & $\begin{array}{l}\text { CSS }-72.72 \% \\
\text { OS }-63.63 \%\end{array}$ & 7.1 \\
\hline Ong et al. ${ }^{[20]}$ & 2010 & 31 & ND & $3.23 \%$ & CSS - $96.77 \%$, OS - $93.55 \%$ & 18 \\
\hline Palou et al. ${ }^{[35]}$ & 2010 & 12 & ND & ND & CSS $-91.67 \%$ & 16.5 \\
\hline Murphy et al. ${ }^{[36]}$ & 2008 & 23 & $26 \%$ overall & Nil & 1 metastatic death & 17 \\
\hline
\end{tabular}

ND: Not described; PFS: progression free survival; OS: overall survival; CSS: cancer specific survival.

\section{DISCUSSION}

Different approaches have been outlined for male NS RARC ${ }^{[15]}$ and this review details the perioperative, oncological and functional outcomes (see Tables 1 and 2). Most series contain small numbers of patients with largely retrospective data with the associated bias of selection. Mean follow up of 27.06 months (range 2.8-58 months) was noted over all in this review. Because of the heterogeneity of study design, technique, definitions and measurements of continence and erectile function and surgeons and centres a meaningful systematic analysis of functional outcomes is challenging.

Though there are differences in defining satisfactory erectile function most encompassing definition derived from all the studies for the purposes of this review was taken as erectile function enough for penetrative sex with or without PDE5i usage. In this review, 54.32\% (range 9\%-100\%) of patients recovered satisfactory erectile function in their post-operative follow up ${ }^{[13,17-38]}$. This is superior to the $12 \%-23.8 \%$ satisfactory erectile function noted on patients who underwent a non-NS radical cystectomy ${ }^{[2,30]}$. 
Continence figures are relevant to those patients undergoing orthotopic neobladder at the same time as male NS RARC and satisfactory continence is defined in the studies to be dry enough to maintain with a maximum of one pad per day. In this review, $85.06 \%$ day time continence rate (range $54.5 \%-100 \%$ ) and $72.48 \%$ night time continence rate (range $46.7 \%$-88\%) were noted overall in patients whose NVBs were preserved $^{[13,1,1,18,20-22,26,29-31,33-40]}$. This is in contrast to the results of some studies, for example, Tyritzis et al. ${ }^{[38]}$, who noted no significant difference in continence rates between their NS and non-NS groups of patients with $88.2 \%$ and $88.9 \%$ respectively for day time continence rates at 12 months.

With the legitimate concerns for NS being the potential for clinical understaging and incomplete tumour excision, it is of note that overall surgical margin negativity was $98.2 \%$ in our review, equivalent to $1.8 \%$ positive surgical margins (PSM) (range 0\%-6.4\%). This compares favourably to other series performing non-NS minimally invasive radical cystectomy achieving $2.2 \% \mathrm{PSM}^{[41]}$ and an overall $6 \%$ found from the results of the International Robotic Cystectomy Consortium ${ }^{[42]}$. Much of this will be explained by patient selection which rules out $\mathrm{pT} 3-4$ tumours, accounting for a significant proportion of PSM cases in other studies.

Examining some of the studies reviewed in more detail, Nyame et al. ${ }^{[26]}$, had a very select patient group of $<$ 40 years old men and performed bilateral nerve and apex sparing radical cystectomy who showed excellent outcomes both oncologically with $0 \%$ PSM and $66.7 \%$ recurrence free survival and functionally with all their patients being potent and continent after 28.3 months follow up. However, the demographics show that bladder cancer affects much older patients, and once again patient selection is critical. Many patients in their late 60s, early 70s may not regard potency as a priority, but this is not always the case, and although patients below the age of 65 years have better outcomes postoperatively with respect to erectile function, older patients should at least be offered the opportunity to maximise their quality of life after treatment ${ }^{[13]}$. Canda et al. ${ }^{\left[{ }^{[0]}\right]}$, investigated 27 patients who underwent RARC with Studer Neobladder and found that such procedures, although technically challenging, have good surgical and pathological outcomes and satisfactory morbidity and functional results. They did caution, however, that further studies with more patients and longer follow-ups are necessary ${ }^{[40]}$. Tyritzis et al. ${ }^{[38]}$, mentioned above, studied functional and oncological outcomes of patients (both male and female) that underwent RARC with totally intracorporeal neobladder. A large proportion of their cohort $(41 / 70 ; 58.6 \%)$ was treated with NS procedures. Sexual function and day time continence at 12 -month was satisfactory at between $70 \%$ and $90 \%$. They supported the findings of Canda et al. ${ }^{[40]}$, that the complications and both functional and oncological outcomes were comparable to open radical cystectomy, demonstrating that RARC with Robotic neobladder and NS approach is a feasible and safe alternative ${ }^{[38]}$. Haberman et al. ${ }^{[27]}$, evaluated the effects on post-operative erectile function of a bilateral cavernosal nerve-sparing approach to RARC in a preoperatively potent population. Their retrospective study reviewed data from 254 patients from 2003 to 2012 who had RARC. 29 out of 33 men under the age of 65 years had bilateral nerve-sparing procedure. Postoperatively, $45 \%$ of them were able to maintain satisfactory erections for penetrative intercourse with or without use of Viagra type medication. A further $21 \%$ recovered erectile function using intracavernosal injections (ICI), while $34 \%$ were unable to use ICI or decided recovering their potency was no longer an issue. They further observed no significant difference between those who recovered potency and those who did not based on a number of parameters, including comorbidities, operating time, tumour stage and age of patient. Despite NS, there was no PSMs and no local cancer recurrence. Based on these results, they concluded that NS RARC improved postoperative erectile function without having to compromise oncologic outcomes ${ }^{[27]}$. Colombo et al. ${ }^{[18]}$, also showed good outcomes in their patient cohort but acknowledged patients were highly selected comprising only $8.8 \%$ of all the patients who had a radical cystectomy during the study period. A similar patient cohort demographic was noted by Haberman et al. ${ }^{[27]}$, with only $11.4 \%$ of their patients having a NS operation and 
$14.2 \%$ by Ong et al. ${ }^{[20]}$. Interestingly addressing the issue of potential PSM from incidental prostate cancer in patients undergoing male NS RARC, Chessa et al. ${ }^{[43]}$, reported no difference in prostate cancer PSM rates.

Prehabilitation, rehabilitation, adjunctive strategies and lifestyle changes

ERAS protocols have been gaining in popularity and are now utilized by most robotic urology centres. Surgeons have recognized the importance of preparing patients for a major operation such as an RARC with a multimodal approach, becoming increasingly part of "prehabilitation" programs, aiming to institute lifestyle changes and improve physical fitness before surgery is undertaken. Preoperative smoking cessation has shown to positively impact post-operative outcomes ${ }^{[4]}$, and, for example, Minella applied prehabilitation tactics in a randomised controlled study group with exercise, nutritional advice and anxiety reducing interventions, finding that patients who went through the program did better than the control group at their 4 -week post-operative functional capacity evaluation ${ }^{[45]}$. Although some of the evidence is conflicting, penile and pelvic floor rehabilitation has been described as part of post-operative follow up for any radical pelvic surgery not only to improve potency but also urinary continence and bowel function postoperatively ${ }^{[46]}$. In fact, the field of bladder cancer surgery may learn from prostatectomists who employ a number of pre-, intra- and post-operative strategies to improve functional outcomes with both urinary continence and erectile function.

With respect to erectile function, maximizing post-operative recovery begins with pre-operative work up when the patient's erectile function is assessed objectively. Modalities may include a thorough clinical assessment to stage the disease, IIEF- 6 questionnaire, psychosocial assessment including partner factors ${ }^{[47]}$, sleep assessment ${ }^{[48]}$ and, if necessary, penile doppler ultrasound ${ }^{[49]}$. Similarly, starting pelvic floor exercises with pelvic floor muscle training (PFMT) before the procedure may benefit post-operative continence in patients undergoing orthotopic neobladder ${ }^{[50]}$. Intra-operative strategies stress the importance of the accessory pudendal arteries preservation for erectile function ${ }^{[51]}$, as well as other techniques such as the application of dehydrated human amniotic membrane which has been proposed to accelerate nerve regeneration ${ }^{[52]}$. Postoperatively a multiple modal approach is advocated for rehabilitation of both erectile and urinary function. Ongoing PFMT as well as biofeedback have been used to improve continence ${ }^{[50]}$. For penile rehabilitation, strategies include phosphodiesterase- 5 inhibitors, intracavernosal injection therapy, vacuum erection devices, MUSE Alprostadil urethral suppository, pelvic floor therapy, penile vibrostimulation, hormonal factor correction, penile implant, hyperbaric oxygen therapy, extracorporeal shockwave therapy, psychosocial therapies and nerve grafting techniques ${ }^{[33]}$.

Clearly not all of these strategies will apply to bladder cancer patients undergoing male NS RARC with or without neobladder, but by inference, patients will likely have less comorbidities, and be highly motivated to gain as much quality of life functionally after their procedure as possible. The success of these strategies for patients undergoing prostate cancer surgery would suggest these adjunctive treatments are worthy of further investigation for the field of bladder cancer surgery.

In conclusion, male NS RARC for appropriately selected patients, in experienced hands will offer good functional outcomes leading to a better quality of life for those patients who benefit. Results from the series reviewed suggest the technique is both feasible and safe, without compromising longer term oncological results. With the more widespread use of ERAS protocols, and the introduction of prehabilitation and lifestyle programs, patients will also be able to contribute more proactively to their functional recovery, and help with the technical success of the operation. In addition to basic surgical expertise, there are a number of adjunctive strategies aiming to improve urinary and erectile function, and the results demonstrated for 
prostate cancer surgery suggests their use in the field of bladder cancer surgery may warrant further investigation.

\section{DECLARATIONS}

\section{Authors' contributions}

Performed data analysis, interpretation and manuscript write up: Thinagaran JKR

Technical description of operative steps, data acquisition: Dovey $\mathrm{Z}$

Review of manuscript: Maqboul F

Review and substantial contributions to conception and design of study: Dovey Z, Wiklund P

\section{Availability of data and materials}

Tables 1 and 2 provide details of the systematic review. Appendix A PRISMA METHODOLOGY. Figures to illustrate NS technique.

\section{Financial support and sponsorship}

None.

\section{Conflicts of interest}

Dr. Dovey Z is Medical Director and stock owner (with certificate of shares) of Medtech Holdings Ltd.

\section{Ethical approval and consent to participate}

Not applicable.

\section{Consent for publication}

Not applicable.

\section{Copyright}

(c) The Author(s) 2021.

\section{REFERENCES}

1. GLOBOCAN 2020. Available from: https://gco.iarc.fr/today/data/factsheets/cancers/30-Bladder-fact-sheet.pdf. [Last accessed on 9 Jun 2021].

2. Mossanen M, Gore JL. The burden of bladder cancer care: direct and indirect costs. Curr Opin Urol 2014;24:487-91. DOI PubMed

3. Leal J, Luengo-Fernandez R, Sullivan R, Witjes AJ. Economic burden of bladder cancer across the European Union. Eur Urol 2016;69:438-47. DOI PubMed

4. Richters A, Aben KKH, Kiemeney LALM. The global burden of urinary bladder cancer: an update. World J Urol 2020;38:1895-904. DOI PubMed PMC

5. Marshall VF, Whitmore WF Jr. A technique for the extension of radical surgery in the treatment of vesical cancer. Cancer 1949;2:4248. DOI PubMed

6. Guru KA, Perlmutter AE, Butt ZM, et al. The learning curve for robot-assisted radical cystectomy. JSLS 2009;13:509-14. DOI PubMed PMC

7. Yuh B, Wilson T, Bochner B, et al. Systematic review and cumulative analysis of oncologic and functional outcomes after robotassisted radical cystectomy. Eur Urol 2015;67:402-22. DOI PubMed

8. Rai BP, Bondad J, Vasdev N, et al. Robotic versus open radical cystectomy for bladder cancer in adults. Cochrane Database Syst Rev 2019;4:CD011903. DOI PubMed PMC

9. Walsh PC, Donker PJ. Impotence following radical prostatectomy: insight into etiology and prevention. J Urol 1982;128:492-7. DOI PubMed

10. Dovey ZS, Tewari AK. Anatomical robotic prostatectomy: technical factors to achieve superb continence and erectile function. Transl Androl Urol 2020;9:887-97. DOI PubMed PMC

11. Tewari AK, Srivastava A, Huang MW, et al. Anatomical grades of nerve sparing: a risk-stratified approach to neural-hammock sparing during robot-assisted radical prostatectomy (RARP). BJU Int 2011;108:984-92. DOI PubMed

12. Collins JW, Tyritzis S, Nyberg T, et al. Robot-assisted radical cystectomy: description of an evolved approach to radical cystectomy. Eur Urol 2013;64:654-63. DOI PubMed

13. Kessler TM, Burkhard FC, Perimenis P. Attempted nerve sparing surgery and age have a significant effect on urinary continence and 
erectile function after radical cystoprostatectomy and ileal orthotopic bladder substitution. J Urol 2004;172:1323-7. DOI PubMed

14. Dotan ZA, Kavanagh K, Yossepowitch O, et al. Positive surgical margins in soft tissue following radical cystectomy for bladder cancer and cancer specific survival. J Urol 2007;178:2308-12. DOI PubMed

15. Huang J, Fan X, Dong W. Current status of laparoscopic and robot-assisted nerve-sparing radical cystectomy in male patients. Asian $J$ Urol 2016;3:150-5. DOI PubMed PMC

16. Qu LG, Lawrentschuk N. Orthotopic neobladder reconstruction: patient selection and perspectives. Res Rep Urol 2019;11:333-41. DOI PubMed PMC

17. Asimakopoulos AD, Campagna A, Gakis G, et al. Nerve sparing, robot-assisted radical cystectomy with intracorporeal bladder substitution in the male. J Urol 2016;196:1549-57. DOI PubMed

18. Colombo R, Pellucchi F, Moschini M, et al. Fifteen-year single-centre experience with three different surgical procedures of nervesparing cystectomy in selected organ-confined bladder cancer patients. World J Urol 2015;33:1389-95. DOI PubMed

19. Jacobs BL, Daignault S, Lee CT, et al. Prostate capsule sparing versus nerve sparing radical cystectomy for bladder cancer: results of a randomized, controlled trial. J Urol 2015;193:64-70. DOI PubMed PMC

20. Ong CH, Schmitt M, Thalmann GN, Studer UE. Individualized seminal vesicle sparing cystoprostatectomy combined with ileal orthotopic bladder substitution achieves good functional results. J Urol 2010;183:1337-41. DOI PubMed

21. Balbay MD, Canda AE, Kiremit MC, Koseoglu E. Intracorporeal studer pouch formation with Balbay's technique following robotic radical cystectomy for bladder cancer: experience with 22 cases with oncologic and functional outcomes. J Endourol 2020;34:273-80. DOI PubMed

22. Gok B, Atmaca AF, Canda AE, et al. Robotic radical cystectomy with intracorporeal studer pouch formation for bladder cancer: experience in ninety-eight cases. J Endourol 2019;33:375-82. DOI PubMed

23. Liu XJ, Liu TY, Xie SX, et al. Nerve-sparing robot-assisted laparoscopic radical cystectomy: clinical application and effect. Zhonghua Nan Ke Xue 2019;25:797-801. PubMed

24. Zarranz JE, Busto L, Crespo I, et al. Robotic-assisted laparoscopic nerve sparing cystectomy. J Urol 2019;201:e675. DOI

25. Kwon SY, Ha Y, Kim T, Kwon TG. Erectile function and long-term oncologic outcomes of nerve-sparing robot-assisted radical cystectomy: comparison with open radical cystectomy. Korean J Urol Oncol 2018;16:32-7. DOI

26. Nyame YA, Zargar H, Ramirez D, et al. Robotic-assisted laparoscopic bilateral nerve sparing and apex preserving cystoprostatectomy in young men with bladder cancer. Urology 2016;94:259-64. DOI PubMed

27. Haberman K, Wittig K, Yuh B, et al. The effect of nerve-sparing robot-assisted radical cystoprostatectomy on erectile function in a preoperatively potent population. J Endourol 2014;28:1352-6. DOI PubMed

28. Menon M, Hemal AK, Tewari A, et al. Nerve-sparing robot-assisted radical cystoprostatectomy and urinary diversion. BJU Int 2003;92:232-6. DOI PubMed

29. Schwentner C, Sim A, Balbay MD, et al. Robot-assisted radical cystectomy and intracorporeal neobladder formation: on the way to a standardized procedure. World J Surg Oncol 2015;13:3. DOI PubMed PMC

30. Krishnan J, Ganeshan V, Autorino R, et al. The role of robotic cysto-prostatectomy with bilateral nerve and apex preservation in young patients with bladder cancer. J Urol 2014;191:e909. DOI

31. Rey D, Helou E, Oderda M, Lopez L, Piechaud PT. Robotic cystoprostatectomy with nerve-sparing approach and intracorporeal construction of Hautmann neobladder: Saint Augustin technique. Eur Urol Suppl 2013;12:eV26. DOI

32. Boc A, Pop CD, Crisan N, Mihaly ZA, Coman I. Robot-assisted radical cystectomy with intracorporeal ileal neobladder-initial experience. Eur Urol Suppl 2013;12:e1179. DOI

33. Jonsson MN, Adding LC, Hosseini A, et al. Robot-assisted radical cystectomy with intracorporeal urinary diversion in patients with transitional cell carcinoma of the bladder Eur Urol 2011;60:1066-73. DOI PubMed

34. Akbulut Z, Canda AE, Ozcan MF, Atmaca AF, Ozdemir AT, Balbay MD. Robot-assisted laparoscopic nerve-sparing radical cystoprostatectomy with bilateral extended lymph node dissection and intracorporeal Studer pouch construction: outcomes of first 12 cases. J Endourol 2011;25:1469-79. DOI PubMed

35. Palou J, Gaya JM, Gausa L, et al. Robotic assisted bilateral nerve sparing cystoprostatectomy combined with ileal orthotopic bladder substitution achieves good functional results. Eur Urol 2010;9:511. DOI

36. Murphy DG, Challacombe BJ, Elhage O, et al. Robotic-assisted laparoscopic radical cystectomy with extracorporeal urinary diversion: initial experience. Eur Urol 2008;54:570-80. DOI PubMed

37. Mottrie A, Carpentier P, Schatteman P, et al. Robot-assisted laparoscopic radical cystectomy: initial experience on 27 consecutive patients. J Robot Surg 2007;1:197-201. DOI PubMed PMC

38. Tyritzis SI, Hosseini A, Collins J, et al. Oncologic, functional, and complications outcomes of robot-assisted radical cystectomy with totally intracorporeal neobladder diversion. Eur Urol 2013;64:734-41. DOI PubMed

39. Palou J, Magana JD, Gausa L, et al. Robotic assisted bilateral nerve sparing cystoprostatectomy. Eur Urol 2017;16:e2401. DOI PubMed

40. Canda AE, Atmaca AF, Altinova S, Akbulut Z, Balbay MD. Robot-assisted nerve-sparing radical cystectomy with bilateral extended pelvic lymph node dissection (PLND) and intracorporeal urinary diversion for bladder cancer: initial experience in 27 cases. BJU Int 2012;110:434-44. DOI PubMed

41. Smith AB, Raynor M, Amling CL, et al. Multi-institutional analysis of robotic radical cystectomy for bladder cancer: perioperative outcomes and complications in 227 patients. J Laparoendosc Adv Surg Tech A 2012;22:17-21. DOI PubMed

42. Elsayed AS, Gibson S, Jing Z, et al. Rates and patterns of recurrences and survival outcomes after robot-assisted radical cystectomy: results from the international robotic cystectomy consortium. J Urol 2021;205:407-13. DOI PubMed 
43. Chessa F, Möller A, Collins J, et al. Oncologic outcomes of patients with incidental prostate cancer who underwent RARC: a comparison between nerve sparing and non-nerve sparing approach. J Robot Surg 2021;15:105-14. DOI PubMed

44. Thomsen T, Villebro N, Møller AM. Interventions for preoperative smoking cessation. Cochrane Database Syst Rev 2014:CD002294. DOI PubMed PMC

45. Minnella EM, Awasthi R, Bousquet-Dion G, et al. Multimodal prehabilitation to enhance functional capacity following radical cystectomy: a randomized controlled trial. Eur Urol Focus 2021;7:132-8. DOI PubMed

46. Aoun F, Peltier A, van Velthoven R. Penile rehabilitation after pelvic cancer surgery. ScientificWorldJournal 2015;2015:876046. DOI PubMed PMC

47. Guercio C, Mehta A. Predictors of patient and partner satisfaction following radical prostatectomy. Sex Med Rev 2018;6:295-301. DOI PubMed PMC

48. Masri S, Sassone-Corsi P. The emerging link between cancer, metabolism, and circadian rhythms. Nat Med 2018;24:1795-803. DOI PubMed PMC

49. Muñoz-rodríguez J, Hannaoui N, Domínguez A, et al. Impact of the baseline study with penile doppler ultrasound in patients with prostate cancer before radical prostatectomy. Actas Urol Esp (Engl Ed) 2019;43:84-90. DOI PubMed

50. Zhang YG, Song QX, Song B, Zhang DL, Zhang W, Wang JY. Diagnosis and treatment of urinary incontinence after orthotopic ileal neobladder in China. Chin Med J (Engl) 2017;130:231-5. DOI PubMed PMC

51. Rogers CG, Trock BP, Walsh PC. Preservation of accessory pudendal arteries during radical retropubic prostatectomy: surgical technique and results. Urology 2004;64:148-51. DOI PubMed

52. Patel VR, Samavedi S, Bates AS, et al. Dehydrated human amnion/chorion membrane allograft nerve wrap around the prostatic neurovascular bundle accelerates early return to continence and potency following robot-assisted radical prostatectomy: propensity score-matched analysis. Eur Urol 2015;67:977-80. DOI PubMed

53. Reece JC, Dangerfield DC, Coombs CJ. End-to-side somatic-to-autonomic nerve grafting to restore erectile function and improve quality of life after radical prostatectomy. Eur Urol 2019;76:189-96. DOI PubMed 